\title{
Dobutamine Infusion and Absence of Pulmonary Hypertension Are Associated with Decreased Mortality in a Cohort of 249 Patients with Cardiogenic Shock
}

\author{
Sébastien Champion*, Bernard A. Gaüzère, David Vandroux, Bruno J. Bouchet, \\ Didier Drouet, Yannick Lefort
}

Réanimation Polyvalente, CHU de la Réunion, Hôpital Félix Guyon, Saint Denis, France

Email: ${ }^{*}$ Champion.seb@wanadoo.fr

Received 25 July 2014; revised 10 September 2014; accepted 27 September 2014

Copyright (C) 2014 by authors and Scientific Research Publishing Inc.

This work is licensed under the Creative Commons Attribution International License (CC BY). http://creativecommons.org/licenses/by/4.0/

\section{(c) (i) Open Access}

\begin{abstract}
Objective: Prognostic analysis of $\mathbf{2 4 9}$ patients admitted for cardiogenic shock (CS) of various origins. Background: Little is known about prognosis of CS from non-ischemic cardiomyopathy. Methods: Retrospective monocentric study of patients referred to an ICU during 2 years. Results: Despite aggressive management including intra-aortic balloon pump (31\%), extra-renal replacement therapy (36\%), extra-corporeal life support (8\%), and catecholamine infusion (97\%), in-hospital mortality was $46 \%$. Toxic CS or CS related to deficiency carried a better outcome (mortality $5 \%$ ). Post-myocardial infarction or post-cardiac arrest CS was associated with higher mortality. In the multivariate analyses, only SAPS II (OR 1.037; 1.013 - 1.056; $p=0.0001)$, pulmonary hypertension (OR 4.8; 1.3 - 17; $p=0.02$ ), extra-renal replacement therapy (OR 2.9; $1.3-6 ; p=0.006$ ), and dobutamine infusion (OR $0.44 ; 0.2-0.96 ; p=0.04$ ) were significantly associated with in-hospital mortality. Conclusion: Dobutamine infusion was associated with a better outcome. Higher SAPS II, pulmonary hypertension, and extra-renal replacement therapy were associated with increased inhospital mortality.
\end{abstract}

\section{Keywords}

Cardiogenic Shock, Myocardial Infarction, Catecholamine, Pulmonary Hypertension, Dobutamine, Critically Ill

\footnotetext{
${ }^{*}$ Corresponding author.
} 


\section{Introduction}

Despite decades of clinical studies, cardiogenic shock (CS) mortality is still around 50\% [1]. CS treatment is based on hemodynamic (medical or instrumental) and respiratory support and the etiologic treatment, urgent revascularization for example [2]. So far, few studies have addressed the choice of inotropes and vasopressors [3][5]. Some authors propose dopamine as a first step. However, in a randomized controlled trial, norepinephrine was associated with lower mortality and arrhythmias compared with dopamine in the sub group of patients with CS [6]. Regarding pure inotropes (named inodilators), levosimendan, phosphodiesterase-3 inhibitors and dobutamine have similar outcomes regarding mortality. The pronounced vasodilator effects (and by non-adrenergic pathway) of both levosimendan and phosphodiesterase-3 inhibitors make them desirable for right heart failure and/or for beta-adrenergic sparing (i.e. previous use of beta-blockers or beta-stimulants with down-regulation). Although not created equal [7], most catecholamines lack proved differences in main outcomes. Managing fixed cardiac index and blood pressure targets with the association of dobutamine and norepinephrine seems easier, in order to control alpha and beta-1 effects. However, which hemodynamic target is the safest and the most efficient is still unknown. In septic and cardiogenic shock patients, randomized controlled trials showed similar outcome with infusion of norepinephrine (+/- dobutamine) vs. epinephrine [8]-[10]. Moreover, microcirculation is poorly evaluated in the management of CS. Indeed, epinephrine is commonly used in our intensive care unit (ICU) as it is the main stress circulating hormone and the final pathway of degradation of amines. Our study main objective is to analyze prognostic related factors (pharmacological, electrolytes and instrumental) in a large cohort of patients with CS.

\section{Methods}

In our teaching hospital, cardiac care is ensured by cardiologists in a coronary care unit, by anesthetists in the postoperative cardiac unit. Most severe patients are referred in our 18 beds general ICU. We performed a 2-year retrospective study concerning all consecutive adult patients admitted for CS in our ICU. CS was defined by the association of shock from cardiac origin on the basis of usual criterion [1]. All patients were classified according to the CS etiology: acute myocardial infarction (AMI), ischemic heart disease, post-cardiac arrest, postoperative (cardiac surgery), toxic, vitamin deficiency, inflammatory and other.

Demographic (age, sex, past medical history), clinical (blood pressure, heart rate, body temperature, upon admission), biological (troponine Ic, B-type natriuretic peptide (BNP), arterial lactates, protidemia upon admission and maximal value, along with electrolytes during ICU stay), and echocardiography data were collected. We calculated the Simplified Acute Physiologic Score 2 (SAPS II) upon admission. Pulse pressure was defined by systolic blood pressure minus diastolic blood pressure. Cardiac index was reported, whenever available. Cardiac power index $\left(\mathrm{W} / \mathrm{m}^{2}\right)$ was calculated as follow: Cardiac index $\left(\mathrm{L} / \mathrm{min} / \mathrm{m}^{2}\right) \times 0.0022 \times$ mean arterial pressure (mmHg). Pulmonary hypertension (PH) was defined by systolic pulmonary artery pressure above $40 \mathrm{mmHg}$. Hypocalcaemia was defined by ionized blood calcium $<1.1 \mathrm{mmol} / \mathrm{L}$, or if unavailable, corrected blood calcium level $<2.1 \mathrm{mmol} / \mathrm{L}$. Hypercalcaemia was defined by blood calcium level above $>2.7 \mathrm{mmol} / \mathrm{L}$.

There was no specific protocol applied in our ward at the time of the study concerning vasoactive agents. Very often, different catecholamines are used over time. So we decided to report the initial catecholamines (prescribed by the attending physician) used as a binary variable, whatever further management in the follow-up. Treatment with beta-blockers, angiotensin converting enzyme inhibitors (ACEI), and statins were collected at time of patient discharge from the ICU. Particular attention was paid on treatment, drugs and mechanical management, and biologic evolution. The main outcome was the in-hospital mortality. The study complies with the declaration of Helsinki.

\section{Statistical Analysis}

Data are expressed as median (25 - 75 percentiles) for continuous variables and number (percent) for binary variables. Qualitative values were compared with Chi-2 tests and quantitative values with Mann-Whitney tests as appropriate. Odd's ratio (OR) for hospital mortality were calculated with their 95\% confidence intervals (CI). A multivariate analysis by logistic regression was performed with different significant values during the univariate analysis. A $p$ value $<0.05$ was considered significant. Statistical analysis was performed with StatView 5.0 (SAS institute). 


\section{Results}

\subsection{Population}

During the study period, 249 patients had CS inclusion criteria. Population description and its management are summarized in Table 1. Briefly, most patients were intubated (89\%), and received catecholamines (97\%). In-hospital mortality was $46 \%$, as expected in CS patients with such high severity markers, including SAPS II at 64 .

\subsection{Electrolytes Management}

Hypocalcaemia was present in 117 (47\%) of the patients during ICU course. Hypercalcaemia was noticed in 13 (5\%) of the patients upon admission, was iatrogenic in 25 (10\%) additional patients and was never severe. Lower blood calcium level during ICU stay was associated with increased length of stay $\left(r^{2}=0.01, p=0.003\right)$, extrarenal replacement therapy (ERRT), mechanical ventilation duration $\left(r^{2}=0.01, p<0.001\right)$, SAPS II $(p=0.03)$. There was a strong trend for lower blood calcium level in non-survivors than in survivors $(p=0.053$, Table 1$)$. However, in a multivariate analysis the association was not significant. Calcium blood level has been normalized in 84 (72\%) of the 117 patients with hypocalcaemia, in 24 hours (8 - 72) on average. Ischemic events or troponin release were similar in all groups (hypercalcaemia, hypocalcaemia, corrected or not). The correction of the hypocalcaemia, the time of correction and hypocalcaemia were not associated with any improvement in hemodynamic parameters, mechanical ventilation duration, or length of stay. Only arrhythmias were associated with hypocalcaemia duration before normalization.

\subsection{Mechanical and Medical Treatments}

Intra-aortic balloon pump (IABP) was inserted in 76 patients (31\%) and was not statistically associated with inhospital mortality (OR 0.67; CI $0.4-1.2 ; p=0.2$ ). Median duration of IABP support was 3 days (2 - 6). Extra-corporeal life support (ECLS) was used in 20 patients for a median 8 days $(3-12)$. ECLS was always used for reversible cause of shock. Nine of the ECLS treated patients died (45\%) and 11 survived. Six ECLS patient had PH or right ventricular (RV) failure: 2 died (33\%) and 4 survived. The survivors had RV AMI, massive mitral regurgitation, fulminant myocarditis or pheochromocytoma while the non-survivors had mitral valve replacement or pulmonary embolism. Of the 18 patients with RV failure, 12 died $(67 \%$, in whom 4 of the 6 pulmonary embolism, 67\%) and 6 survived. Though, mortality of patients with RV failure related CS was high $(10 / 12,83 \%)$ but not statistically different from patients treated with ECLS (Fischer, $p=0.1$ ). The use of inhaled nitric oxide in 17 patients was not associated with a better outcome (OR 0.73 ; CI $0.3-2 ; p=0.5$ ).

Most of patients received catecholamines (241 patients, 97\%): single $(N=167)$, association of two $(N=57)$, three $(N=12)$, or four $(N=5)$ vasoactive agents. When single vasoactive agent was used, it was an inotrope including epinephrine $(N=115)$, dobutamine $(N=33)$, or dopamine $(N=1)$, but also a predominant vasopressor, norepinephrine $(N=18)$. More common associations were epinephrine + dobutamine $(N=35)$, norepinephrine + dobutamine $(N=14)$. The choice of initial catecholamines is summarized in Table 1.

\subsection{Prognosis}

The prognosis analysis is shown in Table 1. In the multivariate analyses, SAPS II (OR 1.037; CI 1.013 - 1.056; $p=0.0001$ ), PH (OR 4.8; CI $1.3-17 ; p=0.02$ ), ERRT (OR 2.9; CI $1.3-6$; $p=0.006$ ), and dobutamine infusion (OR 0.44; CI 0.2 - 0.96; $p=0.04$ ) were significantly associated with in-hospital mortality.

In patients surviving the acute phase, prescription of betablockers $(p=0.002)$, ACEI $(p=0.0001)$, and statins $(p=0.01)$ was associated with improved outcome and decreased in-hospital mortality.

\section{Discussion}

In this 2 years descriptive study of 249 patients with CS of various etiologies, the mortality rate was $46 \%$, as expected in such severe CS patients referred from coronary or cardiac surgery units [1]. Our patients had worse outcomes when the cause was post-infarction or post-cardiac arrest CS. Toxic CS or CS related to deficiency had $5 \%$ mortality rate and this might have decreased the overall mortality. As usual, higher SAPS II was associated with worse outcome, in our study.

We also found that PH was associated with increased mortality (OR 4.8). This had already been reported in 
Table 1. Description of the population and prognosis analysis.

\begin{tabular}{|c|c|c|c|c|}
\hline & Overall patients $(n=249)$ & Survivors $(n=135)$ & Non-survivors (=114) & $p$ value $^{*}$ \\
\hline Female sex & 89 (36\%) & 45 (34\%) & 44 (39\%) & 0.2 \\
\hline Age (years) & $62(48-73)$ & $57(46-71)$ & $67(53-75)$ & 0.002 \\
\hline SAPS II & $64(46-86)$ & $53(38-66)$ & $81(61-102)$ & $<0.0001$ \\
\hline Admission $\mathrm{T}\left({ }^{\circ} \mathrm{C}\right)$ & 35.9 & 36.2 & 35.6 & 0.01 \\
\hline Blood glucose $(\mathrm{mmol} / \mathrm{L})$ & $9.5(6.9-15.5)$ & $8.5(6.3-12.1)$ & $11.3(7.3-16.8)$ & 0.01 \\
\hline Calcium (mmol/L) & $1.87(1.7-2)$ & $1.88(1.8-2)$ & $1.85(1.7-1.9)$ & 0.053 \\
\hline SBP (mmHg) & $100(81-121)$ & $100(82-124)$ & $95(81-119)$ & 0.3 \\
\hline DBP (mmHg) & $55(46-65)$ & $58(50-67)$ & $54(44-65)$ & 0.08 \\
\hline Pulse pressure (mmHg) & $42(30-60)$ & $42(30-68)$ & $43(32-60)$ & 0.6 \\
\hline $\operatorname{HR}(/ \min )$ & $100(79-120)$ & $96(75-115)$ & $110(80-123)$ & 0.048 \\
\hline $\mathrm{CPI}\left(\mathrm{W} / \mathrm{m}^{2}\right)$ & $0.4(0.3-0.5)$ & $0.4(0.3-0.75)$ & $0.3(0.2-0.4)$ & 0.03 \\
\hline LVEF (\%) & $35(20-49)$ & $35(25-50)$ & $30(20-40)$ & 0.01 \\
\hline SPAP (mmHg) & $40(34-55)$ & $39(34-50)$ & $50(40-55)$ & 0.01 \\
\hline \multicolumn{5}{|l|}{ Etiology } \\
\hline - $\quad$ AMI & 79 (32\%) & $33(25 \%)$ & $46(40 \%)$ & 0.007 \\
\hline - Ischemic heart disease & $115(45 \%)$ & $55(41 \%)$ & $60(53 \%)$ & 0.06 \\
\hline - Cardiac arrest & $6(2 \%)$ & 0 & $6(5 \%)$ & 0.007 \\
\hline - Cardiac surgery & 36 (15\%) & $23(17 \%)$ & $13(11 \%)$ & 0.2 \\
\hline - Toxic/carential & $21(8 \%)$ & $20(15 \%)$ & 1 & $<0.0001$ \\
\hline - Inflammatory & $33(13 \%)$ & $23(17 \%)$ & $10(9 \%)$ & 0.052 \\
\hline Admission lactates $(\mathrm{mmol} / \mathrm{L})$ & $4(2-7)$ & $3(2-5)$ & $7(3-12)$ & $<0.0001$ \\
\hline $\mathrm{pH}$ & $7.24(7.14-7.31)$ & $7.28(7.21-7.33)$ & $7.17(7.04-7.25)$ & 0.0008 \\
\hline Creatinin $(\mu \mathrm{mol} / \mathrm{L})$ & $143(103-214)$ & $131(95-193)$ & $161(123-231)$ & 0.003 \\
\hline Peak troponin & $6(1-27)$ & $4(0.4-23)$ & $9(1-48)$ & 0.01 \\
\hline Arrhythmia & & & & \\
\hline - Supraventricular & $63(25 \%)$ & $36(27 \%)$ & $27(24 \%)$ & 0.6 \\
\hline - Ventricular & $29(12 \%)$ & $11(8 \%)$ & $18(16 \%)$ & 0.06 \\
\hline - Conduction disorder & $42(17 \%)$ & $14(10 \%)$ & $28(25 \%)$ & 0.003 \\
\hline MV & $221(89 \%)$ & 108 (81\%) & $113(99 \%)$ & $<0.0001$ \\
\hline Length of MV (days) & $5(2-10)$ & $7(4-11)$ & $2(1-8)$ & $<0.0001$ \\
\hline Catecholamine $\$$ & 241 (97\%) & 129 (96\%) & 112 (98\%) & 0.2 \\
\hline • Epinephrine & 172 (69\%) & 73 (54\%) & 99 (87\%) & $<0.0001$ \\
\hline - Dobutamine & 93 (37\%) & 69 (51\%) & 24 (21\%) & $<0.0001$ \\
\hline - Norepinephrine & $51(21 \%)$ & $36(27 \%)$ & $15(13 \%)$ & 0.01 \\
\hline - Dopamine & 8 (3\%) & $6(4 \%)$ & $2(2 \%)$ & 0.4 \\
\hline - PDE-3 inhibitors & $11(4 \%)$ & $7(5 \%)$ & $4(4 \%)$ & 0.7 \\
\hline IABP & $76(31 \%)$ & $36(27 \%)$ & 40 (35\%) & 0.2 \\
\hline External electro systolic pacing & $11(4 \%)$ & $4(3 \%)$ & 7 (6\%) & $<0.0001$ \\
\hline ERRT & 90 (36\%) & 35 (26\%) & 55 (48\%) & 0.0003 \\
\hline ECLS & 20 (8\%) & $11(8 \%)$ & $9(8 \%)$ & 0.9 \\
\hline LOS ICU (days) & $4(1-10)$ & $6(3-11)$ & $2(1-8)$ & $<0.0001$ \\
\hline
\end{tabular}

SAPS II: Simplified Acute Physiology Score 2; Calcium: lower calcium blood level; SBP: systolic blood pressure; DBP: diastolic blood pressure; HR: heart rate; CPI: cardiac power index; LVEF: left ventricular ejection fraction; SPAP: systolic pulmonary artery pressure; AMI: acute myocardial infarction; MV: mechanical ventilation; PDE-3: phosphodiesterase-3; IABP: intra-aortic balloon pump; ERRT: extra-renal replacement therapy; ECLS: extra-corporeal life support; LOS ICU: length of stay in the intensive care unit. ${ }^{*} p$ values between survivors and non-survivors. ${ }^{\$}$ Catecholamines can be added and total can be more than $100 \%$. 
heart failure patients (HF) [11]. PH may act as venous return "obstruction" and further impair microcirculation [12]. Venous congestion has been consistently associated with worse outcome in HF patients [13]. PH can be seen in more advanced left HF or superimposed RV failure. RV function is very strongly associated with worse outcome [11]. Whenever RV failure develops, particular hemodynamic management with careful volume loading, levosimendan, and inhaled nitric oxide might be required [14]. Inhaled nitric oxide is being evaluated in pulmonary embolism with shock, but was not associated in better outcome in our patients. An important finding of our investigation is the major prognostic impact of PH. To our knowledge, it has been related to adverse outcome in HF but never in CS. The particular benefit of ECLS in case of RV failure is illustrated by our study and discussed latter.

Acute renal failure (ARF) is a common complication of critical illness, which is associated with high mortality. In our study, ERRT was associated with prognosis. This fatality rate can be related to the kidney failure itself which has a separate independent effect on the risk of death. Oliguric ARF is an independent risk factor for ICU mortality, and also after cardiac surgery, complicated STEMI [15], and may be related to ERRT itself. Indeed, ERRT might cause harm. ERRT has been recently associated with a decrease in renal function without a prognosis improvement in a particular subset of HF patients [16]. Therefore in our study, the association of ERRT with poor outcome can be related to either ARF or ERRT itself.

\subsection{Medical Treatment}

In this cohort of CS patients, when used as the first choice catecholamine, dobutamine is significantly and independently associated with an improved outcome and a doubled hospital survival. This beneficial association was present whatever the etiology of CS. In order to increase cardiac output, after volume correction, patients received dobutamine or epinephrine-or the combination of both—as other inotropes like dopamine or phosphodiesterase-3 inhibitors were exceptionally prescribed in our ICU [5]. Accordingly, inodilators (namely, dobutamine, levosimendan, and phosphodiesterase-3 inhibitors) have been associated with decreased mortality (OR 0.66; CI 0.55 - 0.80) after propensity score analysis in 988 patients with CS [17]. Levosimendan is still not approved in our country and its use requires a specific authorization; thereby, it was not available in our hospital. Norepinephrine was sometimes added to dobutamine, or used alone. This was the main predominant vasopressor in our study, as we never infused phenylephrine or vasopressin to our patients (one association with terlipressin). Association of catecholamines is often preferred to separate inotrope from vasopressor effect rather than increasing the amount of a single catecholamine [4]. Though, in order to improve contractility, dobutamine (with the association of norepinephrine and/or another vasopressor) might be preferred over epinephrine in the management of patients with CS.

Nevertheless, despite many described side effects like hyperglycaemia, lactic acidosis [4] [8] [18], or coronary artery thrombosis stimulation [19], to our knowledge, no difference in major clinical outcome between catecholamines has been published in the CS setting, except increased arrhythmias and mortality with dopamine [3] [20]. In our cohort of patient, dobutamine infusion seems a safe and efficient inotrope agent. It can be the first line inotrope even if as epinephrine, dobutamine infusion leads to platelets activation [21].

Discharge treatment is of paramount importance. At recovery from shock, beta-blockers should be introduced. Their use after acute severe HF is associated with better outcome [22]. ACEI have hormonal beneficial properties but induce pronounced vasodilation. Resuming ACEI before surgery can decrease hypotensive episodes and catecholamines support. During CS, systemic vascular resistances are sometimes altered and ACEI might be detrimental. However to our knowledge, no clinical study has addressed this issue and rapid re-introduction, after the acute phase, should be considered with caution. Statins-associated outcome improvement during CS has already been reported [23].

We have also already reported our experiences on phosphorus and coronary stent [24] [25]. Similarly, calcium management in this setting is associated with conflicting results in the literature. Although calcium supplementation can dramatically improve inotropy in some patients, it is not associated with improved outcome in the ICU [26]. Moreover, it has been associated with increased in long-term risk of myocardial infarction. Our data suggest that calcium supplementation does not improve dramatically the evolution and does not lead to ischemic injury in patients with CS. However, even if single electrolytes management could hardly modify patients' evolution, medical screening for severe electrolytes deficiencies and diligent adequate correction may improve outcome [24]. 
Therapeutic hypothermia is regarded as an attractive procedure in post-AMI CS and in order to decrease global oxygen consumption [27]. However, these data deserve scrutiny, as lower initial temperature was associated with increased mortality in our study. This association was found in patients presenting with different causes of shock, i.e. post-myocardial infarction, post cardiac arrest CS. Although for our patients, lower admission temperature was not significantly associated with mortality in the multivariate analysis. Many confounding factors could have impact our results as lower temperatures were recorded in clinically more severe patients. However, we did find an association between a lower admission temperature and the frequency of arrhythmias $(p=0.005)$, especially ventricular ones $(p=0.04)$, but not with other complications such as infection or hemorrhage. In our study only few patients reached hypothermic temperatures $\left(<34^{\circ} \mathrm{C}\right)$, we cannot draw firm conclusion but incite to careful evaluation of systematic lowering of body temperature during CS [28].

\subsection{Mechanical Treatment}

In our study, mechanical treatment had no effect on the outcome. IABP has been widely used for mechanical hemodynamic support, it improves coronary perfusion and decrease afterload with a beneficial effect on oxygen consumption. However its effect is still debated with conflicting results on early and late mortality. Recently, in 600 patients with MI and CS, randomized to IABP or no mechanical treatment, IABP proved to have no effect on short term and long term mortality [29]. Our data are similar. In our hospital, ECLS is used in refractory CS in order to correct the hemodynamic disorders before multiorgan failure develops. We don't have specific protocol and implantation is upon the clinical empirical judgment of the cardiology team in charge (cardiologist, intensivist and cardiac surgeon). ECLS has been implemented in 20 patients. Even if these assisted patients were more severe, mortality was identical (45\%), and one might hypothesize that ECLS can be a lifesaving procedure. To prove the ECLS effect on mortality, studies are needed and require patient selection with a precise and widely acceptable definition of refractory CS (as it does not exist, to our knowledge), and careful, precise and identical medical management.

Among the most severe cases of our cohort, non-responders to dobutamine and/or patients with PH may benefit from more aggressive treatment including assist device. Our data suggest that this population may be selected as refractory CS. CS due to isolated RV failure might gain special benefit from peripheral ECLS as it is a good RV unloading system and increasing the post-charge of a "normal" left ventricle might not lead to further insult. Our six patients with isolated RV failure treated with ECLS had a low mortality (33\%). It was not statistically significant and need further evaluation but in case of reversible cause of shock (mainly pulmonary embolism, pending recovery from fibrinolysis or embolectomy), ECLS might be considered as a rescue and efficient procedure [30].

\section{Limitations}

Our study has several limitations. Mix different etiologies might have impaired our prognosis analysis. On one hand, it adds information on non-ischemic CS, which is rarely described. On the other hand, the disease might be different with different prognosis assessment, as acknowledged. However, a 2-year nationwide registry did not find significant difference between non-ischemic and AMI-related CS [31].

As a monocentric retrospective study, major confounding biases can impact our findings. For example, dobutamine could have been prescribed to less severely ill patients despite adjustment attempts. As we only studied the first catecholamine used, associations or shift in inotropes or vasopressors could have also an effect on hospital mortality in these patients. Though, we can only conclude on the prognosis significance of the choice of the first catecholamine we used. However, after revascularization for post-AMI CS, there is paucity of tough recommendations in the current Guidelines [2]. Retrospective studies can help in evaluating the design for future trials, influence expert opinion and give a picture of the "real life".

Similarly, the role of ERRT and ECLS in case of RV failure is rather hypotheses generating. The large and increasing panel of mechanical devices encompasses the possibility of prospective serious evaluation for precise indication in various settings. Though, retrospective analysis of the results based on clinical judgment is still valuable.

\section{Conclusion}

In cardiogenic shock patients treated with dobutamine had a better outcome. Conversely, higher SAPS II, pul- 
monary hypertension, and extra-renal replacement therapy were associated with increased in-hospital mortality.

\section{Acknowledgements}

Michel Bohrer and Emmanuel Shirpaz for data extraction. The authors declare that there is no conflict of interests regarding the publication of this paper.

\section{References}

[1] Thiele, H., Allam, B., Chatellier, G., Schuler, G. and Lafont, A. (2010) Shock in Acute Myocardial Infarction: The Cape Horn for trials? European Heart Journal, 31, 1828-1835. http://dx.doi.org/10.1093/eurheartj/ehq220

[2] McMurray, J.J., Adamopoulos, S., Anker, S.D., Auricchio, A., Böhm, M., Dickstein, K., Falk, V., Filippatos, G., Fonseca, C., Gomez-Sanchez, M.A., Jaarsma, T., Køber, L., Lip, G.Y., Maggioni, A.P., Parkhomenko, A., Pieske, B.M., Popescu, B.A., Rønnevik, P.K., Rutten, F.H., Schwitter, J., Seferovic, P., Stepinska, J., Trindade, P.T., Voors, A.A., Zannad, F., Zeiher, A., Task Force for the Diagnosis and Treatment of Acute and Chronic Heart Failure 2012 of the European Society of Cardiology, Bax, J.J., Baumgartner, H., Ceconi, C., Dean, V., Deaton, C., Fagard, R., FunckBrentano, C., Hasdai, D., Hoes, A., Kirchhof, P., Knuuti, J., Kolh, P., McDonagh, T., Moulin, C., Popescu, B.A., Reiner, Z., Sechtem, U., Sirnes, P.A., Tendera, M., Torbicki, A., Vahanian, A., Windecker, S., McDonagh, T., Sechtem, U., Bonet, L.A., Avraamides, P., Ben Lamin, H.A., Brignole, M., Coca, A., Cowburn, P., Dargie, H., Elliott, P., Flachskampf, F.A., Guida, G.F., Hardman, S., Iung, B., Merkely, B., Mueller, C., Nanas, J.N., Nielsen, O.W., Orn, S., Parissis, J.T. and Ponikowski, P., ESC Committee for Practice Guidelines (2012) ESC Guidelines for the Diagnosis and Treatment of Acute and Chronic Heart Failure 2012: The Task Force for the Diagnosis and Treatment of Acute and Chronic Heart Failure 2012 of the European Society of Cardiology. Developed in Collaboration with the Heart Failure Association (HFA) of the ESC. European Journal of Heart Failure, 14, 803-869. http://dx.doi.org/10.1093/eurjhf/hfs105

[3] Bangash, M.N., Kong, M.L. and Pearse, R.M. (2012) Use of Inotropes and Vasopressor Agents in Critically Ill Patients. British Journal of Pharmacology, 165, 2015-2033. http://dx.doi.org/10.1111/j.1476-5381.2011.01588.x

[4] Overgaard, C.B. and Dzavík, V. (2008) Inotropes and Vasopressors: Review of Physiology and Clinical Use in Cardiovascular Disease. Circulation, 118, 1047-1056. http://dx.doi.org/10.1161/CIRCULATIONAHA.107.728840

[5] Hollenberg, S.M. (2011) Vasoactive Drugs in Circulatory Shock. American Journal of Respiratory and Critical Care Medicine, 183, 847-855. http://dx.doi.org/10.1164/rccm.201006-0972CI

[6] De Backer, D., Biston, P., Devriendt, J., Madl, C., Chochrad, D., Aldecoa, C., Brasseur, A., Defrance, P., Gottignies, P., Vincent, J.L. and SOAP II Investigators (2010) Comparison of Dopamine and Norepinephrine in the Treatment of Shock. New England Journal of Medicine, 362, 779-789. http://dx.doi.org/10.1056/NEJMoa0907118

[7] Carpati, C.M., Astiz, M.E. and Rackow, E.C. (1997) Optimizing Gastric Mucosal Perfusion: All Catecholamines May Not Be Created Equal. Critical Care Medicine, 25, 1624-1625. http://dx.doi.org/10.1097/00003246-199710000-00004

[8] Levy, B., Perez, P., Perny, J., Thivilier, C. and Gerard, A. (2011) Comparison of Norepinephrine-Dobutamine to Epinephrine for Hemodynamics, Lactate Metabolism, and Organ Function Variables in Cardiogenic Shock. A Prospective, Randomized Pilot Study. Critical Care Medicine, 39, 450-455. http://dx.doi.org/10.1097/CCM.0b013e3181ffe0eb

[9] Annane, D., Vignon, P., Renault, A., Bollaert, P.E., Charpentier, C., Martin, C., Troché, G., Ricard, J.D., Nitenberg, G., Papazian, L., Azoulay, E. And Bellissant, E., CATS Study Group (2007) Norepinephrine plus Dobutamine versus Epinephrine Alone for Management of Septic Shock: A Randomised Trial. Lancet, 370, 676-684. http://dx.doi.org/10.1016/S0140-6736(07)61344-0

[10] Myburgh, J.A., Higgins, A., Jovanovska, A., Lipman, J., Ramakrishnan, N. and Santamaria, J., CAT Study Investigators (2008) A Comparison of Epinephrine and Norepinephrine in Critically Ill Patients. Intensive Care Medicine, 34, 2226-2234. http://dx.doi.org/10.1007/s00134-008-1219-0

[11] Georgiopoulou, V.V., Kalogeropoulos, A.P., Borlaug, B.A., Gheorghiade, M. and Butler, J. (2013) Left Ventricular Dysfunction with Pulmonary Hypertension: Part 1: Epidemiology, Pathophysiology, and Definitions. Circulation: Heart Failure, 6, 344-354. http://dx.doi.org/10.1161/CIRCHEARTFAILURE.112.000095

[12] Vellinga, N.A., Ince, C. and Boerma, E.C. (2013) Elevated Central Venous Pressure Is Associated with Impairment of Microcirculatory Blood Flow in Sepsis: A Hypothesis Generating Post Hoc Analysis. BMC Anesthesiology, 13, 17. http://dx.doi.org/10.1186/1471-2253-13-17

[13] Damman, K., van Deursen, V.M., Navis, G., Voors, A.A., van Veldhuisen, D.J. and Hillege, H.L. (2009) Increased Central Venous Pressure Is Associated with Impaired Renal Function and Mortality in a Broad Spectrum of Patients with Cardiovascular Disease. Journal of the American College of Cardiology, 53, 582-588. http://dx.doi.org/10.1016/j.jacc.2008.08.080

[14] Mebazaa, A., Karpati, P., Renaud, E. and Algotsson, L. (2004) Acute Right Ventricular Failure—From Pathophysiol- 
ogy to New Treatments. Intensive Care Medicine, 30, 185-196. http://dx.doi.org/10.1007/s00134-003-2025-3

[15] Lesage, A., Ramakers, M., Daubin, C., Verrier, V., Beynier, D., Charbonneau, P. and Cheyron, D. (2004) Complicated Acute Myocardial Infarction Requiring Mechanical Ventilation in the Intensive Care Unit: Prognostic Factors of Clinical Outcome in a Series of 157 Patients. Critical Care Medicine, 32, 100-105. http://dx.doi.org/10.1097/01.CCM.0000098605.58349.76

[16] Bart, B.A., Goldsmith, S.R., Lee, K.L., Givertz, M.M.. O’Connor, C.M., Bull, D.A., Redfield, M.M., Deswal, A., Rouleau, J.L., LeWinter, M.M., Ofili, E.O., Stevenson, L.W., Semigran, M.J., Felker, G.M., Chen, H.H., Hernandez, A.F., Anstrom, K.J., McNulty, S.E., Velazquez, E.J., Ibarra, J.C., Mascette, A.M. and Braunwald, E. (2012) Ultrafiltration in Decompensated Heart Failure with Cardiorenal Syndrome. The New England Journal of Medicine, 367, 2296-2304. http://dx.doi.org/10.1056/nejmoa1210357

[17] Pirracchio, R., Parenica, J., Rigon, M.R., Chevret, S., Spinar, J., Jarkovsky, J., Zannad, F., Alla, F. and Mebazaa, A. (2013) The Effectiveness of Inodilators in Reducing Short Term Mortality among Patient with Severe Cardiogenic Shock: A Propensity-Based Analysis. PLoS ONE, 8, e71659. http://dx.doi.org/10.1371/journal.pone.0071659

[18] Agrawal, R., Al-Khafaji, A. and Yende, S. (2010) Epinephrine: Is It Really the Black Sheep of Vasoactive Agents? Critical Care, 14, 309. http://dx.doi.org/10.1186/cc8998

[19] Lin, H. and Young, D.B. (1995) Opposing Effects of Plasma Epinephrine and Norepinephrine on Coronary Thrombosis in Vivo. Circulation, 91, 1135-1142. http://dx.doi.org/10.1161/01.CIR.91.4.1135

[20] Havel, C., Arrich, J., Losert, H., Gamper, G., Müllner, M. and Herkner, H. (2011) Vasopressors for Hypotensive Shock. Cochrane Database of Systematic Reviews, 5, Article ID: CD003709.

[21] Galloway, M.T., Paglieroni, T.G., Wun, T., Arena, F.J. and Lewis, W.R. (1998) Platelet Activation during Dobutamine Stress Echocardiography. American Heart Journal, 135, 888-900. http://dx.doi.org/10.1016/S0002-8703(98)70051-1

[22] Böhm, M., Link, A., Cai, D., Nieminen, M.S., Filippatos, G.S., Salem, R., Cohen Solal A., Huang, B., Padley, R.J., Kivikko, M. and Mebazaa, A. (2011) Beneficial Association of $\beta$-Blocker Therapy on Recovery from Severe Acute Heart Failure Treatment: Data from the Survival of Patients with Acute Heart Failure in Need of Intravenous Inotropic Support Trial. Critical Care Medicine, 39, 940-944. http://dx.doi.org/10.1097/CCM.0b013e31820a91ed

[23] Champion, S. (2014) Statins for Patients with Cardiogenic Shock. Korean Circulation Journal, 44, $200-202$. http://dx.doi.org/10.4070/kcj.2014.44.3.200

[24] Champion, S., Gaüzère, B.A. and Vandroux, D. (2012) Hypophosphatemia in Patients with Cardiogenic Shock. Journal of Critical Care, 27, 511. http://dx.doi.org/10.1016/j.jcrc.2012.07.018

[25] Champion, S., Gaüzère, B.A. and Lefort, Y. (2012) Drug-Eluting Stents Should Not Be Used in ST-Elevated Myocardial Infarction with Cardiogenic Shock. Archives of Internal Medicine, 172, 1613-1614. http://dx.doi.org/10.1001/archinternmed.2012.4418

[26] Forsythe, R.M., Wessel, C.B., Billiar, T.R., Angus, D.C. and Rosengart, M.R. (2008) Parenteral Calcium for Intensive Care Unit Patients. Cochrane Database of Systematic Reviews, 8, Article ID: CD006163.

[27] Stegman, B.M., Newby, L.K., Hochman, J.S. and Ohman, E.M. (2012) Post-Myocardial Infarction Cardiogenic Shock Is a Systemic Illness in Need of Systemic Treatment: Is Therapeutic Hypothermia One Possibility? Journal of the American College of Cardiology, 59, 644-647. http://dx.doi.org/10.1016/j.jacc.2011.11.010

[28] Champion, S., Deye, N., Mégarbane, B. and Baud, F.J. (2013) Should All Out-of-Hospital Cardiac Arrest Patients Presenting with Cardiogenic Shock Be Treated with Therapeutic Hypothermia? Critical Care Medicine, 41, e6-e7. http://dx.doi.org/10.1097/CCM.0b013e318270e28e

[29] Thiele, H., Zeymer, U., Neumann, F.J., Ferenc, M., Olbrich, H.G., Hausleiter, J., Richardt, G., Hennersdorf, M., Empen, K., Fuernau, G., Desch, S., Eitel, I., Hambrecht, R., Fuhrmann, J., Böhm, M., Ebelt, H., Schneider, S., Schuler, G. and Werdan, K. (2012) Intraaortic Balloon Support for Myocardial Infarction with Cardiogenic Shock. The New England Journal of Medicine, 367, 1287-1296. http://dx.doi.org/10.1056/nejmoa1208410

[30] Maggio, P., Hemmila, M., Haft, J. and Bartlett, R. (2007) Extracorporeal Life Support for Massive Pulmonary Embolism. Journal of Trauma-Injury Infection \& Critical Care, 62, 570-576. http://dx.doi.org/10.1097/TA.0b013e318031cd0c

[31] Krenn, L. and Karth, G.D. (2011) Essential Lessons in Cardiogenic Shock: Epinephrine versus Norepinephrine/Dobutamine. Critical Care Medicine, 39, 583-584. http://dx.doi.org/10.1097/CCM.0b013e318208e381 
Scientific Research Publishing (SCIRP) is one of the largest Open Access journal publishers. It is currently publishing more than 200 open access, online, peer-reviewed journals covering a wide range of academic disciplines. SCIRP serves the worldwide academic communities and contributes to the progress and application of science with its publication.

Other selected journals from SCIRP are listed as below. Submit your manuscript to us via either submit@scirp.org or Online Submission Portal.
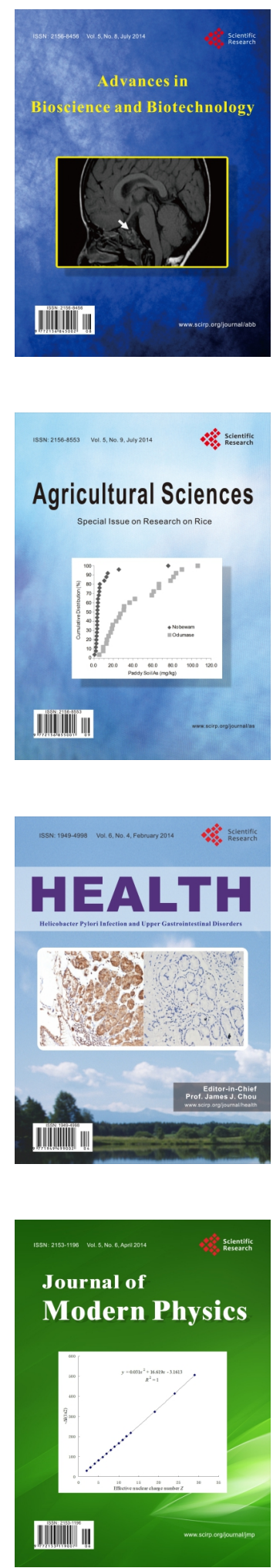
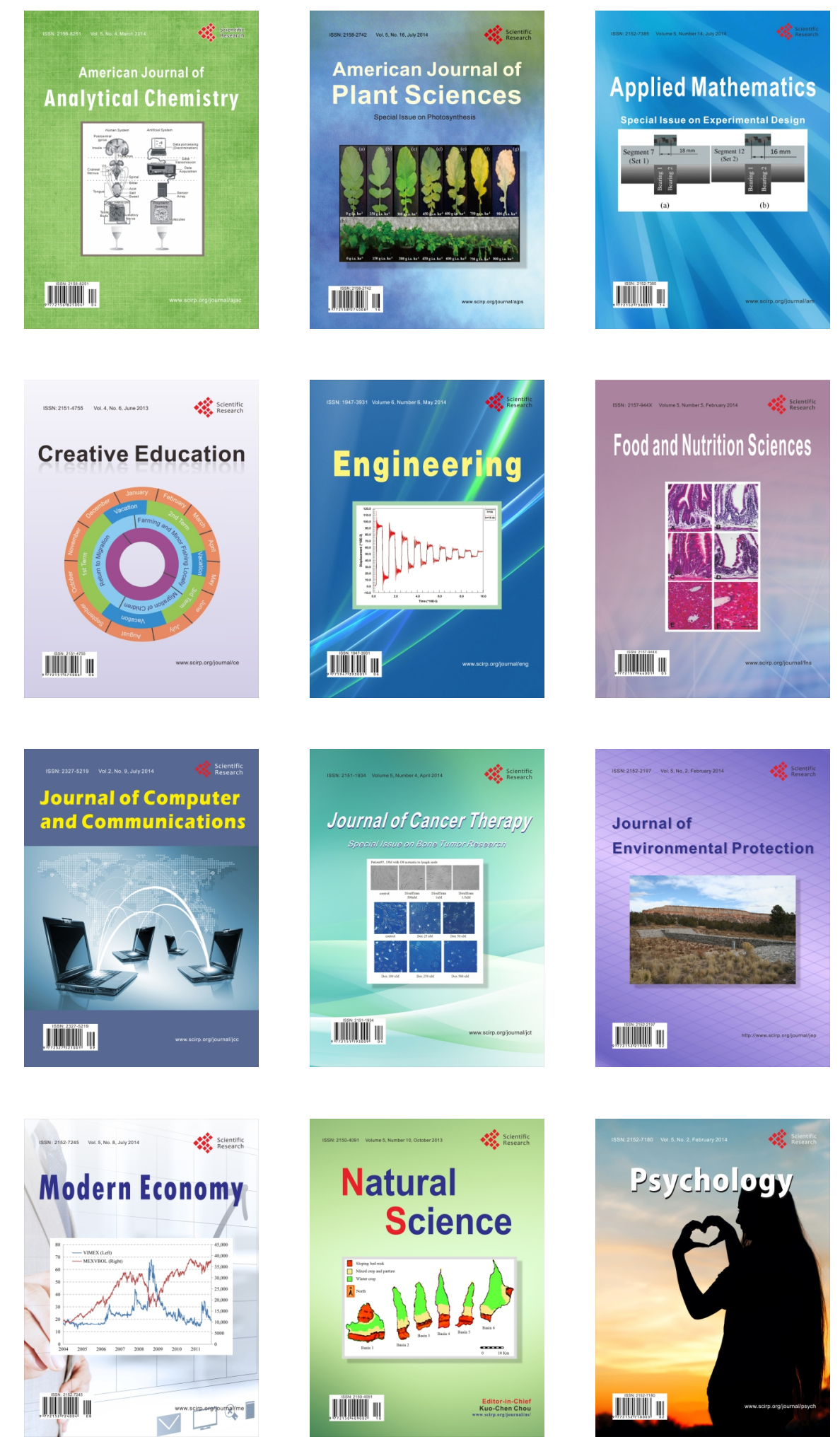